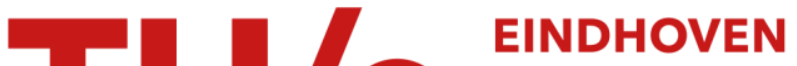 \\ UNIVERSITY OF \\ TECHNOLOGY
}

\section{The impact of operating conditions on post-injection efficacy; a study using design-of-experiments}

Citation for published version (APA):

Willems, R., Bakker, P. C., Dreezen, R., \& Somers, B. (2018). The impact of operating conditions on postinjection efficacy; a study using design-of-experiments. SAE Technical Papers, (2018-01-0229).

https://doi.org/10.4271/2018-01-0229

DOI:

10.4271/2018-01-0229

Document status and date:

Published: 01/01/2018

Document Version:

Accepted manuscript including changes made at the peer-review stage

Please check the document version of this publication:

- A submitted manuscript is the version of the article upon submission and before peer-review. There can be important differences between the submitted version and the official published version of record. People interested in the research are advised to contact the author for the final version of the publication, or visit the $\mathrm{DOI}$ to the publisher's website.

- The final author version and the galley proof are versions of the publication after peer review.

- The final published version features the final layout of the paper including the volume, issue and page numbers.

Link to publication

\section{General rights}

Copyright and moral rights for the publications made accessible in the public portal are retained by the authors and/or other copyright owners and it is a condition of accessing publications that users recognise and abide by the legal requirements associated with these rights.

- Users may download and print one copy of any publication from the public portal for the purpose of private study or research.

- You may not further distribute the material or use it for any profit-making activity or commercial gain

- You may freely distribute the URL identifying the publication in the public portal.

If the publication is distributed under the terms of Article $25 \mathrm{fa}$ of the Dutch Copyright Act, indicated by the "Taverne" license above, please follow below link for the End User Agreement:

www.tue.nl/taverne

Take down policy

If you believe that this document breaches copyright please contact us at:

openaccess@tue.nl

providing details and we will investigate your claim. 


\title{
The Impact of Operating Conditions on Post-Injection Efficacy; a Study Using Design-of-Experiments
}

\author{
Author, co-author (Do NOT enter this information. It will be pulled from participant tab in \\ MyTechZone) \\ Affiliation (Do NOT enter this information. It will be pulled from participant tab in MyTechZone)
}

\begin{abstract}
Post-injection strategies prove to be a valuable option for reducing soot emission, but experimental results often differ from publication to publication. These discrepancies are likely caused by the selected operating conditions and engine hardware in separate studies. Efforts to optimize not only engine-out soot, but simultaneously fuel economy and emissions of nitrogen oxides (NOx) complicate the understanding of post-injection effects even more. Still, the large amount of published work on the topic is gradually forming a consensus. In the current work, a Design-of-Experiments (DoE) procedure and regression analysis are used to investigate the influence of various operating conditions on post-injection scheduling and efficacy. The study targets emission reductions of soot and NOx, as well as fuel economy improvements. Experiments are conducted on a heavy-duty compression ignition engine at three load-speed combinations. Regression analysis shows that the eventual decrease in engine-out soot heavily depends on the air-excess ratio. This observation supports the suggestion that enhanced late-cycle mixing of fuel and oxidizer is an important contributor to observed soot reductions. Furthermore, simultaneous reductions in emissions of NOx and fuel consumption with little or no impact on soot are obtained for particular injection scheduling at low load. At higher engine speed and load, soot reductions are preserved, although shifting the NOx-soot trade-off is more difficult to establish. It was found that rate of exhaust gas recirculation (EGR), timing of the main injection event and fuel pressure generally need careful adjustment to make optimal use of a post-injection scheme. Finally, several points of attention for post-injection scheduling and selecting appropriate operating parameter settings are listed.
\end{abstract}

\section{Introduction}

The use of post-injections in diesel engine combustion has been widely studied throughout recent years, primarily driven by significant advancements in the capabilities of fuel injection equipment. Especially the soot reduction capabilities of postinjections have been reported, for both light-duty [1-4] and heavyduty [5-7] applications. Although these merits to soot reduction are frequently reported, responses to the applied injection strategy often differ, likely linked to the chosen operating conditions and engine hardware in separate studies. Common explanations for the efficacy of soot reduction by post-injections are enhanced mixing of fuel and oxidizer and an increased temperature late in the combustion cycle, as discussed in a review paper by O'Connor and Musculus [8]. The post-injected reacting jet pushes fresh oxygen and combustion radicals (e.g., hydroxyl) into the main soot clouds resulting in better utilization of the available in-cylinder air and thereby promoting latecycle oxidation reactions. This improved mixing is probably complemented by an increased temperature, although it is difficult to isolate separate effects.

If timed and quantified correctly, the aforementioned benefits in engine-out soot are generally accompanied by only marginal or even negligible increases in fuel consumption and NOx emissions. In some cases, even favorable shifts of the NOx-soot trade-off have been established $[1,9,10,11]$, but not without tuning other operating parameter settings as well. Exhaust gas recirculation (EGR) has proven to be a valuable control parameter in most of these studies. Improvements to indicated efficiency by use of a post-injection compared to single injection operation have been reported as well [79]. An acceleration of the burn-out phase and consequent enhancement of the thermodynamic cycle efficiency is a plausible explanation for this, as for example hypothesized by Desantes et al. [7]. To what extent reduced heat losses play a role in such efficiency gains are, to the authors' knowledge, never been charted. Splitting the heat release by using two or more injections could be beneficial. The heat loss reduction is either caused by lower peak values of heat release rate or a shorter interaction duration between spray and piston bowl. The formerly mentioned discrepancies between published results are even further complicated when NOx emissions and fuel economy are incorporated in the analysis.

Engine hardware plays a significant role in post-injection efficacy as well. The eventual position of late-burning fuel and soot pockets rely on the geometrical designs of the piston and injector nozzle, as these determine the spray direction upon spray-bowl contact. Hence, the extent of interaction between a post-jet and the main combustion remnants will also depend on these designs. Horibe et al. [12] have investigated post-injection strategies using several combinations of piston bowl and injector nozzle geometries. It was found that the soot reduction response to post-injection timing flattens when the number of nozzle holes is increased. A similar trend was found when a reentrant piston bowl was replaced by a straight-sided variant [13]. Above all, the studies of Horibe and co-workers stress the importance of careful engine hardware selection when employing multipleinjection strategies.

To deal with the complexity of optimizing diesel engine combustion using multiple injection strategies, some groups have adopted similar Design-of-Experiments (DoE) procedures, although approaches 
somewhat vary. Montgomery and Reitz $[14,15]$ have studied doubleinjection strategies while varying several operating conditions, such as injection pressure, boost pressure and EGR rate. They used fractional factorial experiments to generate a first-order polynomial of a predefined objective function. The gradient of the polynomial is determined and more experiments are conducted in the direction of the projected optimum. If necessary, the procedure is iteratively repeated with smaller intervals between factor values to find the actual optimum. Despite the efficient tracking of extrema, the method is inherently superficial from a fundamental point-of-view (i.e., physicochemical reasons why something is happening). D'Ambrosio and Ferrari [16] have instead complemented their multiple-injection DoE efforts with a three-zone combustion model to back-up their measurement data. This approach proved effective in explaining observed trends.

Martin et al. [17] have published a comprehensive study to distill general guidelines for timing and quantifying post-injections with a focus on soot reduction. From their work, it was found that in the closed-coupled regime (i.e., a short separation between the main and post-injection) timing of the post-injection is the crucial factor for reducing soot, whereas in the long-dwell regime the quantity of postinjected fuel proved more influential. It was further concluded that close-coupled post-injections result in minor reductions of soot emission with slight enhancements to fuel economy, but at the expense of higher NOx emissions. Long-dwell post-injections, on the other hand, result in a large reduction of soot emission with little impact on fuel economy. Other operational parameters were kept constant in their work; hence, conclusive remarks on how these settings would influence the results cannot be made.

The current study uses DoE and regression analysis to structurally investigate the interaction of post-injection scheduling with the airexcess ratio, fuel pressure and combustion phasing, whereas engine hardware is left out of the equation. Three load-speed combinations (A25, A50 and B50) from the European Stationary Cycle (ESC) are selected for the experiments. The aim of this work is to provide general guidelines for post-injection scheduling and selecting appropriate operating conditions for the ESC modes under investigation. It targets soot and NOx emission reductions, as well as fuel economy improvements.

\section{Experiment setup}

A full-metal DAF XEC engine running on European diesel fuel (EN590 specification) is used for the experiments. Three of its six cylinders run on the stock engine control unit to set and control engine speed. In combination with a Schenck W450 eddy-current dynamometer a stable rotational speed is maintained. One dedicated test cylinder has its own isolated air path and fueling system. The original piston has been replaced with a contemporary double-step design. Further engine specifications and nominal operating conditions are shown in Table 1, whereas a schematic overview of the experimental setup is depicted in Figure 1.

An air-driven Resato HPU200-625-2 pump is used to set the target fuel pressure in the common rail, while a Delphi DFi21 injector provides the opportunity to inject multiple fuel pulses per cycle with minimal hydraulic delay $(\sim 200 \mu \mathrm{s})$. Boost pressure is controlled by an external compressor in combination with a reduction valve, and a heater element is set to provide an intake manifold temperature of 40 ${ }^{\circ} \mathrm{C}$. To generate high-pressure EGR, a backpressure valve is installed in the exhaust, which is set to provide a 0.5 bar pressure difference with respect to the intake side. A third valve subsequently controls Page 2 of 13 the EGR rate. Exhaust gas is cooled to approximately $30{ }^{\circ} \mathrm{C}$ before entering the intake manifold. Surge tanks are installed in the air path to achieve sufficient mixing and to dampen fluctuations.

Table 1. Engine hardware specifications and nominal operating conditions.

\begin{tabular}{|l|l|}
\hline Displaced volume & $2097 \mathrm{cc}$ \\
\hline Stroke & $158 \mathrm{~mm}$ \\
\hline Bore & $130 \mathrm{~mm}$ \\
\hline Compression ratio & $15.85: 1$ \\
\hline Number of valves & 4 \\
\hline Intake valve open & $344^{\circ} \mathrm{CA}$ aTDC \\
\hline Intake valve closed & $-153^{\circ} \mathrm{CA}$ aTDC \\
\hline Exhaust valve open & $128^{\circ} \mathrm{CA}$ aTDC \\
\hline Exhaust valve closed & $-346^{\circ} \mathrm{CA}$ aTDC \\
\hline Umbrella angle & $139^{\circ}$ \\
\hline Number of holes & 7 \\
\hline Hole size & $0.195 \mathrm{~mm}$ \\
\hline A25 load / speed & 7 bar (net IMEP) / 1200 rpm \\
\hline A50 load / speed & 13 bar (net IMEP) / 1200 rpm \\
\hline B50 load / speed & 13 bar (net IMEP) / 1425 rpm \\
\hline Intake manifold temperature & $40{ }^{\circ} \mathrm{C}$ \\
\hline Fuel & EN590 specification diesel \\
\hline
\end{tabular}

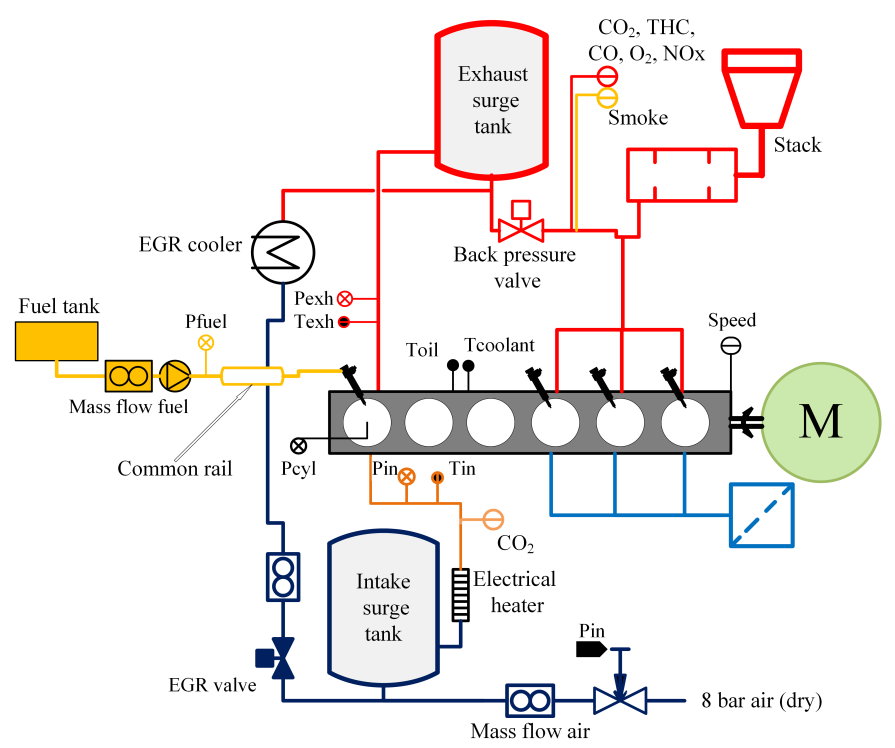

Figure 1. Schematic of the engine test setup including the relevant indication. Some color coding has been applied to illustrate the hot (red) and cold (blue) side of the setup.

An AVL GU21C uncooled transducer is used to measure in-cylinder pressure, and crank angle information is provided by a Heidenhain ROD 4203600 rotary encoder. Fuel consumption and air flow are measured by Micro Motion CMF010M and CMF200M mass flow meters, respectively. Gaseous emissions ( $\mathrm{CO}, \mathrm{NOx}, \mathrm{THC}, \mathrm{CO}_{2}$ and $\mathrm{O}_{2}$ ) and air-excess ratios are analyzed with a Horiba Mexa 7100 DEGR system, while particulate matter (PM) is detected by an AVL $415 \mathrm{~s}$ smoke meter using the paper filter method. The smoke meter sample volume is set to $2000 \mathrm{ml}$ to attain sufficient measurement 
accuracy and precision. Furthermore, three samples are taken and averaged for each experimental run. Filter smoke numbers (FSN) are converted to soot mass (CРM) using the correlation by Christian et al. [18] shown in Equation 1.

$$
\mathrm{C}_{\mathrm{PM}}=4.95 \cdot \mathrm{FSN} \cdot 0.405^{-1} \cdot \exp (0.38 \cdot \mathrm{FSN})
$$

Northrop et al. [19] have quite recently re-evaluated several empirical expressions available in literature. It was found that the expression used here provides the most accurate estimate of soot mass, and is valid even for the extreme low FSN values seen in modern engines.

\section{Methodology}

\section{Experiment matrices}

A DoE approach is used to cover a large variety of operating conditions and post-injection schedules. DoE enables the possibility to study their interaction without the need of measuring all possible combinations. Two central composite design (CCD) matrices are constructed using Matlab's ccdesign for each of the three load-speed points: one for a single injection scheme and one for a post-injection strategy, resulting in six experiment matrices in total. The factors and levels used in the CCD matrices are depicted in Table 2 (A25), Table 3 (A50) and Table 4 (B50). The grey shaded parts indicate the factors and levels used only in post-injection experiments, for dwell and split are not applicable to single injections. Fuel pressure levels for A50 and B50 have been increased compared to A25, as is customary to prevent excessive injection durations at increased load. Moreover, boost pressure is elevated for these higher loads to attain acceptable air-excess ratios.

Table 2. Selected factors and levels for A25. The grey shaded parts indicate post-injection factors and levels that are not used in the single injection experiments. Axial points $(-\alpha$ and $\alpha)$ for single injection experiments are depicted within parentheses.

\begin{tabular}{|l|l|l|l|l|l|l|}
\hline A25 & $-\alpha$ & -1 & $\mathbf{0}$ & 1 & $\alpha$ & Unit \\
\hline SOA main & $-15(-13)$ & -10.5 & $\mathbf{- 8}$ & -5.5 & $-1(-3)$ & ${ }^{\circ}$ aTDC \\
\hline Fuel pres. & $1025(1125)$ & 1250 & $\mathbf{1 3 7 5}$ & 1500 & $1725(1625)$ & bar \\
\hline EGR & $15(17)$ & 20 & $\mathbf{2 3}$ & 26 & $31(29)$ & $\%$ \\
\hline Boost & $1.4(1.45)$ & 1.5 & $\mathbf{1 . 5 5}$ & 1.6 & $1.7(1.65)$ & bar \\
\hline Dwell & 7 & 17 & $\mathbf{2 3}$ & 29 & 39 & ${ }^{\circ} \mathrm{CA}$ \\
\hline Split & 3.5 & 10 & $\mathbf{1 3 . 5}$ & 17 & 23.5 & $\%$ \\
\hline
\end{tabular}

Table 3. Selected factors and levels for A50. The advance of main injection timing is limited to reduce excessive in-cylinder peak pressures. Injection dwell values are significantly decreased with respect to A25.

\begin{tabular}{|l|l|l|l|l|l|l|}
\hline A50 & $-\alpha$ & -1 & $\mathbf{0}$ & 1 & $\alpha$ & Unit \\
\hline SOA main & $-13.5(-12)$ & -10 & $\mathbf{- 8}$ & -6 & $-2.5(-4)$ & ${ }^{\circ}$ aTDC \\
\hline Fuel pres. & $1225(1325)$ & 1450 & $\mathbf{1 5 7 5}$ & 1700 & $1925(1825)$ & bar \\
\hline EGR & $14(16)$ & 19 & $\mathbf{2 2}$ & 25 & $30(28)$ & $\%$ \\
\hline Boost & $1.9(2.0)$ & 2.1 & $\mathbf{2 . 2}$ & 2.3 & $2.5(2.4)$ & bar \\
\hline Dwell & 3 & 7.5 & $\mathbf{1 0}$ & 12.5 & 17 & ${ }^{\circ} \mathrm{CA}$ \\
\hline Split & 3.5 & 10 & $\mathbf{1 3 . 5}$ & 17 & 23.5 & $\%$ \\
\hline
\end{tabular}

At the base of a CCD lays a full factorial matrix consisting of two levels (-1 and 1). This means that all possible combinations between these two levels are run. The full factorial matrix is then complemented with a center point (0), which is a unique combination of factor levels. Center point values are based on a contemporary calibration of a similar engine which utilizes solely single injections. This calibration will act as a reference point and each factor is varied around this reference. The center point is repeated multiple times on random occasions in the experiments to quantify measurement error and to detect possible drift.

Axial points ( $-\alpha$ and $\alpha$ ) are added to complete the CCD by setting one factor to an extreme value while all other factors are kept in their center point level. Relative positions of the axial points with respect to the center point are determined using Equation 2, which are subsequently converted to the physical quantities shown in Table 2, Table 3 and Table 4.

$$
\pm \alpha= \pm \sqrt[4]{2^{\mathrm{k}}}
$$

Here, $\mathrm{k}$ is the number of input factors. Since the value of $\alpha$ depends on the number of inputs, the positions of the axial points thus differ between single injection (4 factors) and post-injection ( 6 factors) experiments. In Table 2, Table 3 and Table 4, the axial points for single injection experiments are indicated within parentheses. All axial points are run twice to check measurement repeatability in boundary regions of the experiment matrix. The total number of experimental runs per load-speed combination equals 39 for the single injection matrices $\left(2^{4}\right.$ factorial points +16 axial points +7 center points) and 103 for the post-injection matrices $\left(2^{6}\right.$ factorial points +24 axial points +15 center points).

Dwell is in this work defined as the crank angle interval between the end of actuation (EOA) of the main injection and start of actuation (SOA) of the post-injection. Note that this dwell 'demand' is not necessarily equal to the physical injection separation, as actual values might depend on the applied actuation duration and can besides differ between injectors. Split is the target mass percentage of the total fuel amount supplied during the post-injection event.

Table 4. Selected factors and levels for B50. Main injection timing is slightly advanced with respect to A50 to account for the increased engine speed.

\begin{tabular}{|l|l|l|l|l|l|l|}
\hline B50 & $-\alpha$ & -1 & $\mathbf{0}$ & 1 & $\alpha$ & Unit \\
\hline SOA main & $-14.75(-13.5)$ & -12 & $\mathbf{- 1 0 . 5}$ & -9 & $-6.25(-7.5)$ & ${ }^{\circ}$ aTDC \\
\hline Fuel pres. & $1225(1325)$ & 1450 & $\mathbf{1 5 7 5}$ & 1700 & $1925(1825)$ & bar \\
\hline EGR & $14(16)$ & 19 & $\mathbf{2 2}$ & 25 & $30(28)$ & $\%$ \\
\hline Boost & $1.9(2.0)$ & 2.1 & $\mathbf{2 . 2}$ & 2.3 & $2.5(2.4)$ & bar \\
\hline Dwell & 3 & 7.5 & $\mathbf{1 0}$ & 12.5 & 17 & ${ }^{\circ} \mathrm{CA}$ \\
\hline Split & 5.5 & 10 & $\mathbf{1 2 . 5}$ & 15 & 19.5 & $\%$ \\
\hline
\end{tabular}

Three ESC points (A25, A50 and B50) are selected for experiments, which exclude high load and high speed operation. In large parts of Europe, trucks mostly operate on flat roads during highway cruising. The relatively low loads and speeds chosen in this work are therefore common scenarios; hence, potential improvements to fuel economy and reductions in emissions can have a large impact on total cost of operation. This makes the application of multiple-injection strategies an interesting option for the selected load-speed combinations. 
The A-speed of this engine corresponds to $1200 \mathrm{rpm}$, whereas the Bspeed equals $1425 \mathrm{rpm}$. Target fuel quantities are $83 \mathrm{mg}$ per cycle for A25 and $140 \mathrm{mg}$ per cycle for both A50 and B50. Since total injected fuel mass is kept constant for each of the load-speed points, postinjection fuel is subtracted from the main injection event. For the post-injection experiments, the energizing time of the main injection is first set to obtain the desired fuel quantity based on the current split value. Thereafter, a post-injection is added and its energizing time is adjusted until the total target fuel quantity is reached. This approach will advance EOA of the main injection in the post-injection experiments, while its SOA remains unaffected; this is illustrated in Figure 2. Typical apparent rate of heat release (aROHR) traces are shown for reference. Common rail pressure during the post-injection experiment is also shown. Note in particular the fluctuations in fuel pressure that occur upon the main injection event. As these wave dynamics affect the fuel pressure at SOA of the post-injection, the energizing time of the post-injection needs adjustment when dwell values are varied.

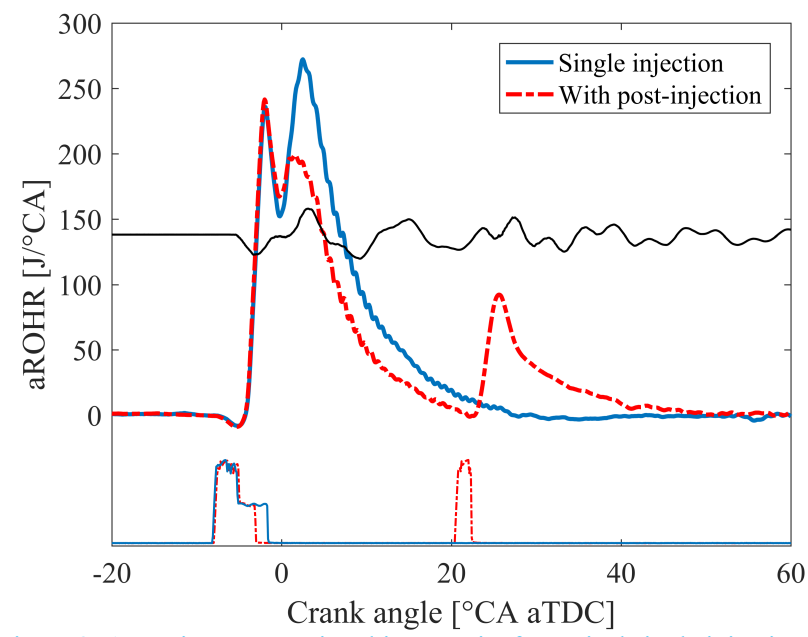

Figure 2. Actuation currents in arbitrary units for typical single injection and post-injection strategies employed in this work. Corresponding aROHR traces are shown for reference. The common rail pressure for the post-injection experiment is shown in MPa.

All experimental runs are used in the regression procedure with the exception of A25 (Table 2), which was run with a broad dwell range from 7 up to $39^{\circ} \mathrm{CA}$. The rationale behind this approach was to be sure to capture the relevant response behavior. However, after assessment of the results it was found that dwell values above 29 ${ }^{\circ} \mathrm{CA}$ had excessive negative impact on engine efficiency. Both combustion efficiency (thus high THC and CO) and thermal efficiency deteriorated, rendering these operational conditions undesired. It was therefore decided to exclude these long-dwell conditions from the regression procedure and further analysis. The dwell range has been scaled down accordingly in the remaining two ESC points, as shown in Table 3 and Table 4.

\section{Regression procedure}

Quadratic regression polynomials are fitted to the experimental data obtained from the DoE test matrices. Net indicated specific NOx and PM emissions as well as fuel consumption are selected as response variables. The response variables along with their adjusted $\mathrm{R}^{2}$ values are shown in Table 5, for single injection and post-injection tests at all three ESC points.

Page 4 of 13
Table 5. Selected response variables and corresponding adjusted $\mathrm{R}^{2}$ values for both single injection and post-injection experiments.

\begin{tabular}{|l|l|l|l|l|l|l|}
\hline & \multicolumn{3}{|l|}{ Single injection } & \multicolumn{3}{l|}{ With Post-injection } \\
\hline & $\underline{\mathrm{A} 25}$ & $\underline{\mathrm{A} 50}$ & $\underline{\mathrm{B} 50}$ & $\underline{\mathrm{A} 25}$ & $\underline{\mathrm{A} 50}$ & $\underline{\underline{\mathrm{B} 50}}$ \\
\hline ISFC & 0.803 & 0.813 & 0.891 & 0.909 & 0.933 & 0.831 \\
\hline ISNOx & 0.969 & 0.947 & 0.988 & 0.990 & 0.959 & 0.982 \\
\hline ISPM & 0.965 & 0.954 & 0.960 & 0.962 & 0.958 & 0.922 \\
\hline
\end{tabular}

First, single factor and quadratic terms are assessed for significance based on individual p-values. Next, interaction terms are added one by one and similarly tested for significance. A p-value below 0.05 is considered 'significant', although caution is advised when assigning significance to a term using a single - somewhat arbitrary - criterion. To further support the significance of individual terms, the adjusted $\mathrm{R}^{2}$ values are checked. Terms are only added to the polynomials if they contribute to a higher adjusted $\mathrm{R}^{2}$. The process is continued up to three-factor interactions. An example polynomial consisting of two factors is shown in Equation 3.

$$
Y=\beta_{0}+\beta_{1} x_{1}+\beta_{2} x_{2}+\beta_{3} x_{1}^{2}+\beta_{4} x_{2}^{2}+\beta_{5} x_{1} x_{2}
$$

Here, $\beta_{i}$ are the polynomial coefficients, $x_{i}$ are the selected operating parameters and $\mathrm{Y}$ is the response variable. An assumption involved with the described method is that measurement samples are presumed to be taken from a normal distribution. Given the typical exponential response that especially engine-out emissions exhibit for a given input parameter (e.g. EGR rate), this assumption does not necessarily hold. It was found that, even for the limited range in which operational inputs were varied in this study, the PM emission samples deviated from normality. Instead, a lognormal distribution proved more suitable and for this reason a log transformation was done on the ISPM response before fitting regression polynomials.

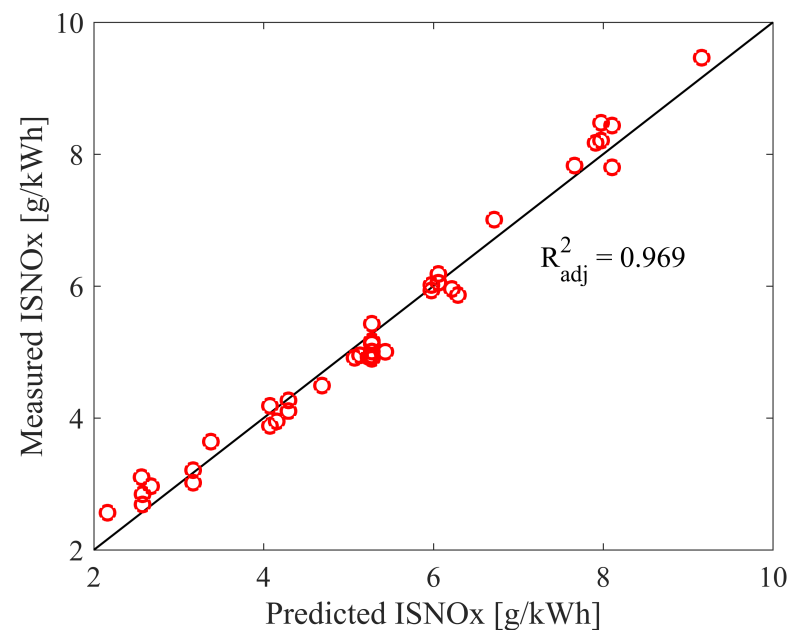

Figure 3. Measured versus predicted ISNOx values for single injection experiments at mode $\mathrm{A} 25$.

The resulting polynomials are tested for validity prior to any further analysis. Residuals (i.e., the difference between predicted and measured values) are plotted to find possible flaws in the experiments and fitting procedures. Two types of residual plots are created for each data set. First, the residuals are plotted versus the measurement number in chronological order. If any unanticipated drift has occurred during experiments a trend will be visible. Second, residuals are 
plotted as function of predicted data to assess whether an appropriate polynomial degree is selected. Again, a trend will show when the fit does not describe all behavior seen in the observations. A plot of predicted versus measured values is made to assess the final regression polynomial. As an example, measured versus predicted specific NOx emission values for single injection experiments at A25 are shown in Figure 3. It can be seen that all points randomly scatter around the trend line, indicating a proper fit. The quality of the fit is further substantiated by an adjusted $\mathrm{R}^{2}$ value close to one.

Eventually, response plots are graphically assessed to observe predicted response behavior with respect to actual measurements. One of such plots is shown in Figure 4, where ISNOx is plotted as function of SOA for A25 single injection experiments. The black solid line shows the predicted response and a $95 \%$ confidence interval is indicated with a shaded region around the prediction. It can be seen that the confidence interval slightly expands towards the axial points. This broadening is a direct result of the lower amount of samples in this boundary region, and similar behavior will be observed in presented graphs throughout this paper. In Figure 4, actual measured values are shown with red circles. It can be seen that the prediction closely follows the measurements; a typical decreasing trend in ISNOx is seen for retarded injection timing. The center point is depicted with error bars that visualizes the standard deviation around the mean of 7 measurements.

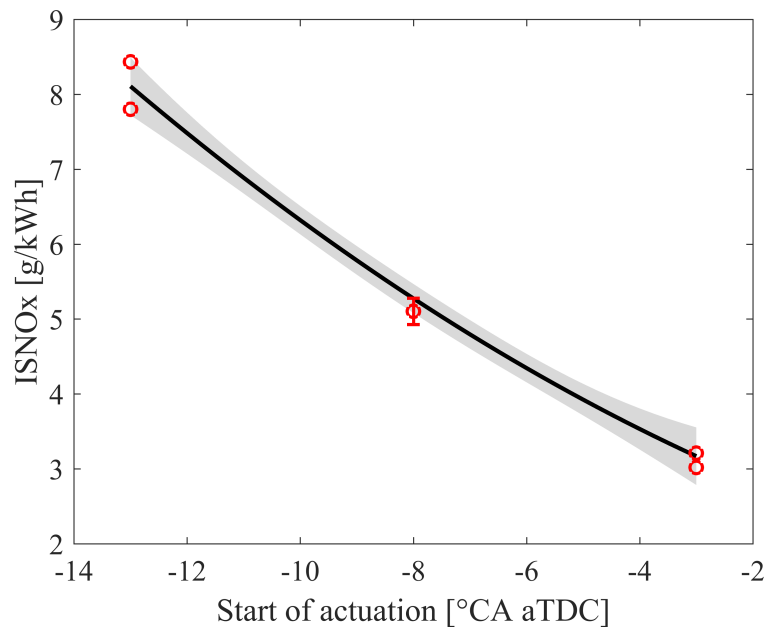

Figure 4. An example response plot of ISNOx emissions as function of SOA. The prediction corresponds to a single injection case at mode A25.

\section{Results and discussion}

To assess the impact of operating conditions on post-injection efficacy several trade-offs of ISFC and ISPM with ISNOx are presented. Particular attention will be given to effects of air-excess ratio (i.e., varying EGR rates and boost pressures), main injection timing and fuel pressure. This approach is meant to give insight into how operating conditions could be adjusted to take full advantage of a post-injection strategy. Single injection experiments will be incorporated in the analysis for reference. Further, response surfaces of ISFC, ISNOx and ISPM are treated to address the interaction of injection dwell and fuel split while keeping other operational parameters fixed in their respective center point values. This gives an idea how quantity and timing of the post-injection interact and eventually will determine its efficacy. The analysis is first directed to a low load and nominal engine speed of $1200 \mathrm{rpm}$ (A25). Thereafter, an investigation is done to assess how the efficacy and scheduling Page 5 of 13 requirements of a post-injection change at higher load (A50). Last, the same methodology is applied for increased engine speed (B50).

\section{A25 - Air-excess ratio and combustion phasing effects}

Figure 5 shows predicted trade-offs of fuel consumption and ISNOx emissions at $20 \%$ (top) and $26 \%$ (bottom) EGR rate. Main injection timing is equally varied along each curve from -3 to $-13{ }^{\circ} \mathrm{CA}$ aTDC (left to right), while post-injection dwell $\left(17^{\circ} \mathrm{CA}\right)$ and split $(17 \%)$ are fixed. Several observations can be noted from this figure.
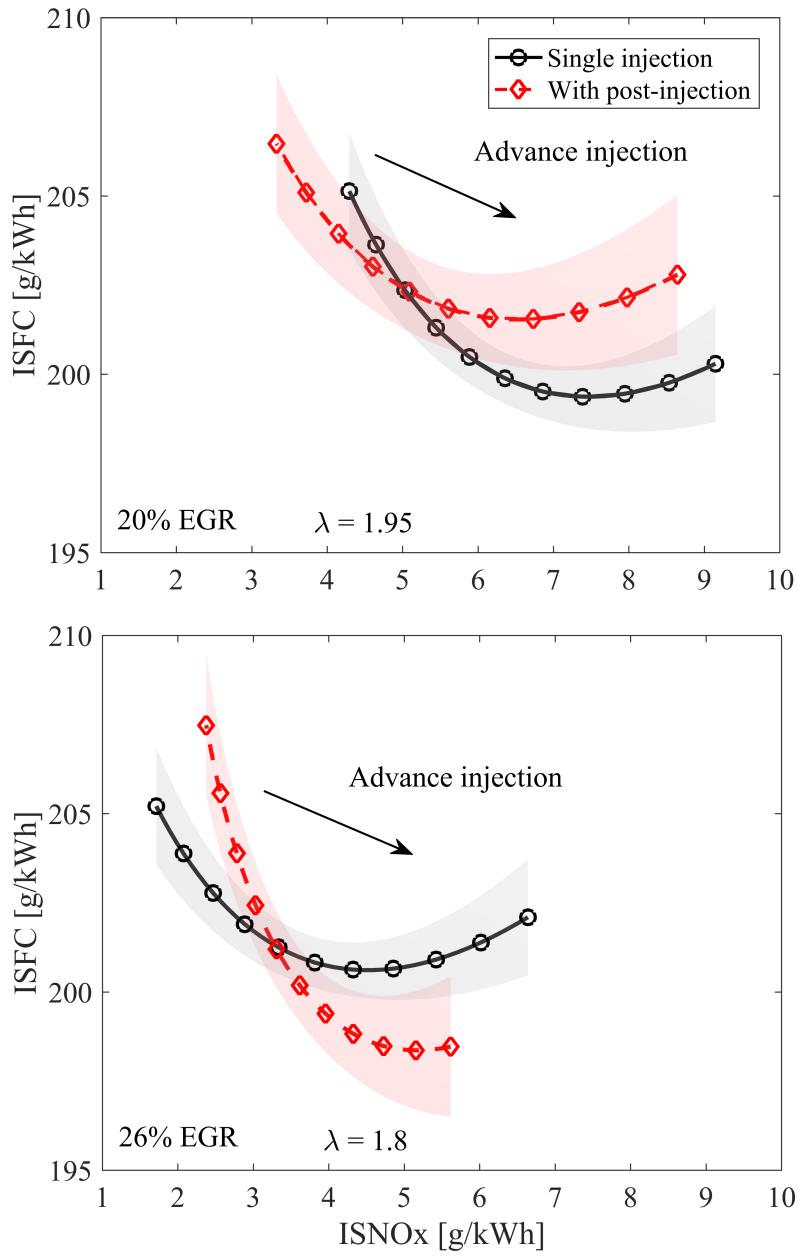

Figure 5. Predicted trade-off of ISFC and ISNOx. Single injections (black solid lines) are compared to a particular post-injection scheme (red dashed lines). Markers are added to indicate fixed main injection timings with intervals of $1{ }^{\circ} \mathrm{CA}$. Air-excess ratio $(\lambda)$ values are shown for reference. Boost and fuel pressure are kept constant at respectively 1.6 and 1250 bar.

At $20 \%$ EGR, the post-injection strategy reduces NOx levels over the entire range of main injection timings. Intuitively, this reduction would be a consequence of the fact that post-injected fuel is supplied during the expansion stroke, effectively suppressing NOx formation rates. Still, in-cylinder temperature is far from homogeneous in diffusion-limited combustion and the NOx formation rate is largely dictated by local conditions. It is possible that a post-injection will produce NOx when it transports fresh air and combustion radicals into hot (partially) burnt gases from the main injection. As residence time at a global high temperature will be reduced when a postinjection is applied, an increase in NOx can be ascribed to a higher 
momentary local temperature. Some evidence of this is found in the bottom graph of Figure 5, where the EGR rate is increased to 26\%. It can be seen that for retarded main injection timing, NOx emissions are higher in the post-injection scheme compared to single main injection operation. Despite that the post-injection SOA is surpassing $20{ }^{\circ} \mathrm{CA}$ aTDC, NOx formation is promoted.

The top graph in Figure 5 illustrates that ISFC is generally lower at constant NOx when adopting a single injection strategy at 20\% EGR. Reason for the single injection scheme to perform better is revealed by heat release analysis indicating overall shorter burn durations. However, a remarkable shift is seen when EGR is increased to $26 \%$. The elevated EGR rate allows considerable advancement of the combustion phasing for the post-injection strategy, which is reflected by the position of the fuel consumption optimum. Contrarily, the optimal SOA of the single injection scheme seems hardly affected. Despite that burn durations are still mostly shorter for the single injection scheme, the post-injection strategy performs significantly better. This can partly be accounted for by a shift of CA50 towards TDC. Reduced heat loss rates to the piston bowl or cylinder wall are expected to play a role here. As formerly mentioned, this reduced heat loss is either caused by reduced peak values of heat release rate (see for example Figure 2) with evident impact on the in-cylinder temperature history, or shorter duration of spray-bowl interaction (reduced convective heat losses). The question is how competing mechanisms of heat loss, combustion phasing and burn duration contribute to the eventual efficiency, and how this balance changes when EGR rate or injection strategy is adapted. The answer is likely ambiguous, and definitely needs more dedicated research.

In Figure 6, soot-NOx trade-offs are shown for operating conditions corresponding to Figure 5. For both EGR rates, the sooting tendency to combustion phasing is lower with the post-injection scheme, which is displayed by more moderate slopes. Especially at retarded main injection timing, a post-injection can greatly reduce PM emissions. As the burn-out phase is shifted further into the expansion stroke, soot oxidation rates decline, giving rise to relatively high engine-out PM levels. A post-injection can be of aid at this point by locally increasing temperature and supplying fresh air to oxygen-depleted regions, as ofttimes proposed in work by other research groups $[9,10$, 17]. When advancing the main injection, this soot reduction is gradually declining and eventually turns into an increase for both EGR rates. At such early combustion phasing, burn-out takes place closer to TDC when in-cylinder density and temperature are still high, resulting in more effective oxidation of soot. Supplying a part of the fuel later in the cycle by introducing a post-injection does not serve the intended purpose of improved oxidation then.

To summarize, the graphs presented in Figure 5 and Figure 6 show distinct impact of EGR rate (i.e., air-excess ratio) and main injection timing to post-injection efficacy at low load and nomimal engine speed. Increasing EGR rate and advancing the main injection timing simultaneously shows potential to lower both fuel consumption and NOx emissions. Contrarily, PM emissions increase at early combustion phasing in these particular conditions, revealing that existing trade-offs are not easily broken. Still, at 26\% EGR and roughly $5 \mathrm{~g} / \mathrm{kWh}$ ISNOx a significant fuel consumption benefit is seen without much impact on PM emissions. Moreover, for conditions where increasing the EGR rate or retarding the main injection timing is limited by PM emissions, appropriate scheduling of the post injection is a valuable tool to increase the tolerance to dilution or combustion phasing.
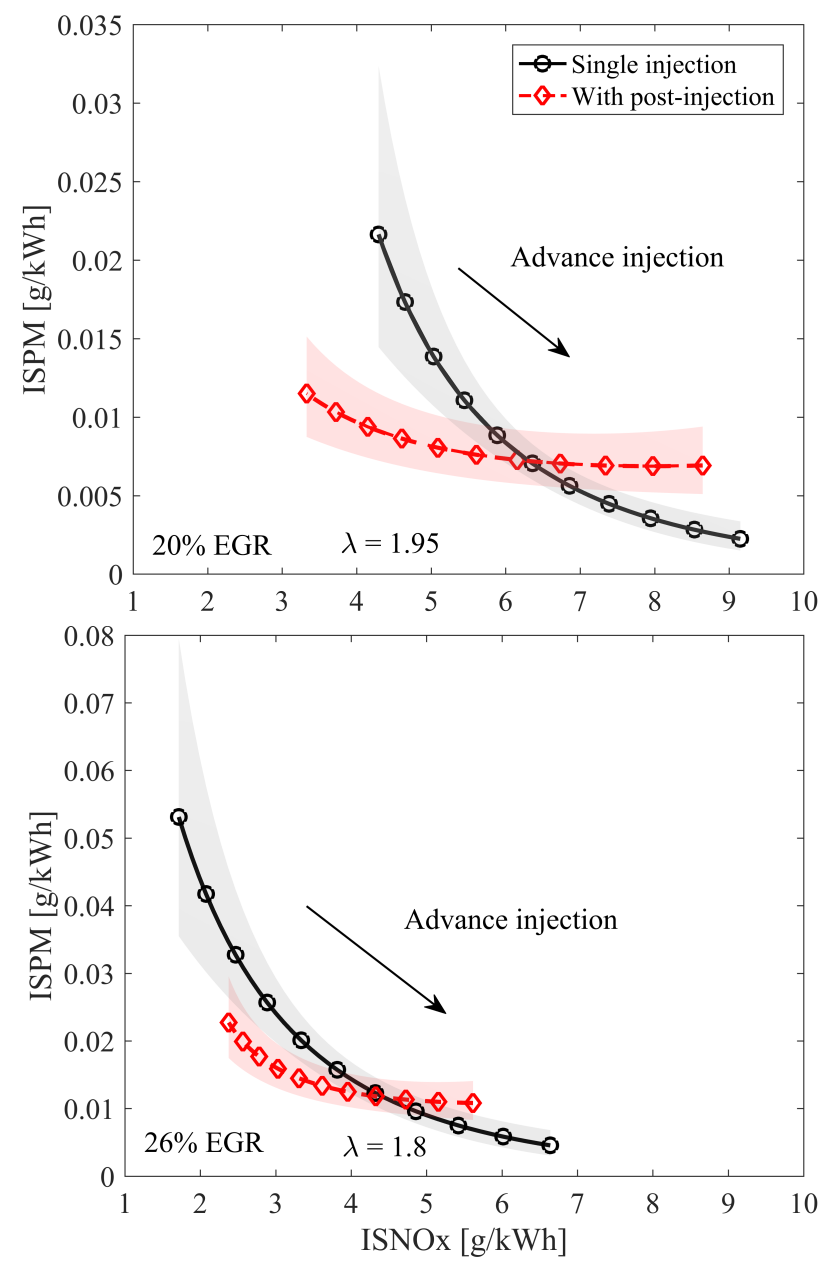

Figure 6. Predicted trade-off of ISPM and ISNOx emissions corresponding to the operating conditions in Figure 5.

\section{A25 - Soot reduction capabilities}

The influence of air-excess ratio on soot reduction by post-injections is assessed and optimal injection dwell values are sought under such varying oxygen availabilities. Lowering the air-excess ratio is readily achieved by increasing the EGR rate. Alternatively, one can reduce boost pressure while keeping the EGR rate constant to obtain similar air-excess ratios. In Figure 7, the response of ISPM to injection dwell is shown for three levels of boost pressure and EGR rates. All other operating parameters are set to their center point values as formerly introduced in Table 2. Predicted single pulse PM levels are shown with dashed horizontal lines in corresponding colors.

At first glance, the striking resemblance between the two graphs is noticed. Imposed variations in air-excess ratio are nearly identical for shown increments in EGR rate and decrements in boost pressure, and range roughly from 1.4 to 1.6 . The resulting responses to injection dwell are similar as well, as can be clearly observed. Optimal dwell values decrease as the air-excess ratio goes down by either increasing EGR or lowering boost pressure. It is thought that depletion of oxygen in the soot clouds originating from the main combustion event occurs earlier in the cycle, hence the need for reduced dwell times. This hypothesis suggests that indeed enhanced late-cycle mixing of combustible gases and particles with oxidizer plays an 
important role in the soot reduction capabilities of post-injection strategies. Moreover, both graphs show that the eventual relative soot reduction increases when air-excess ratios are lowered, which further substantiates the idea of enhanced mixing as primary mechanism in soot oxidation improvements. This finding is in accordance with results from previous work of, for example, Pandurangi et al. [20]. Their modeling efforts indicate that soot oxidation by molecular oxygen is strongly enhanced when employing a post-injection, particularly at elevated EGR rates.
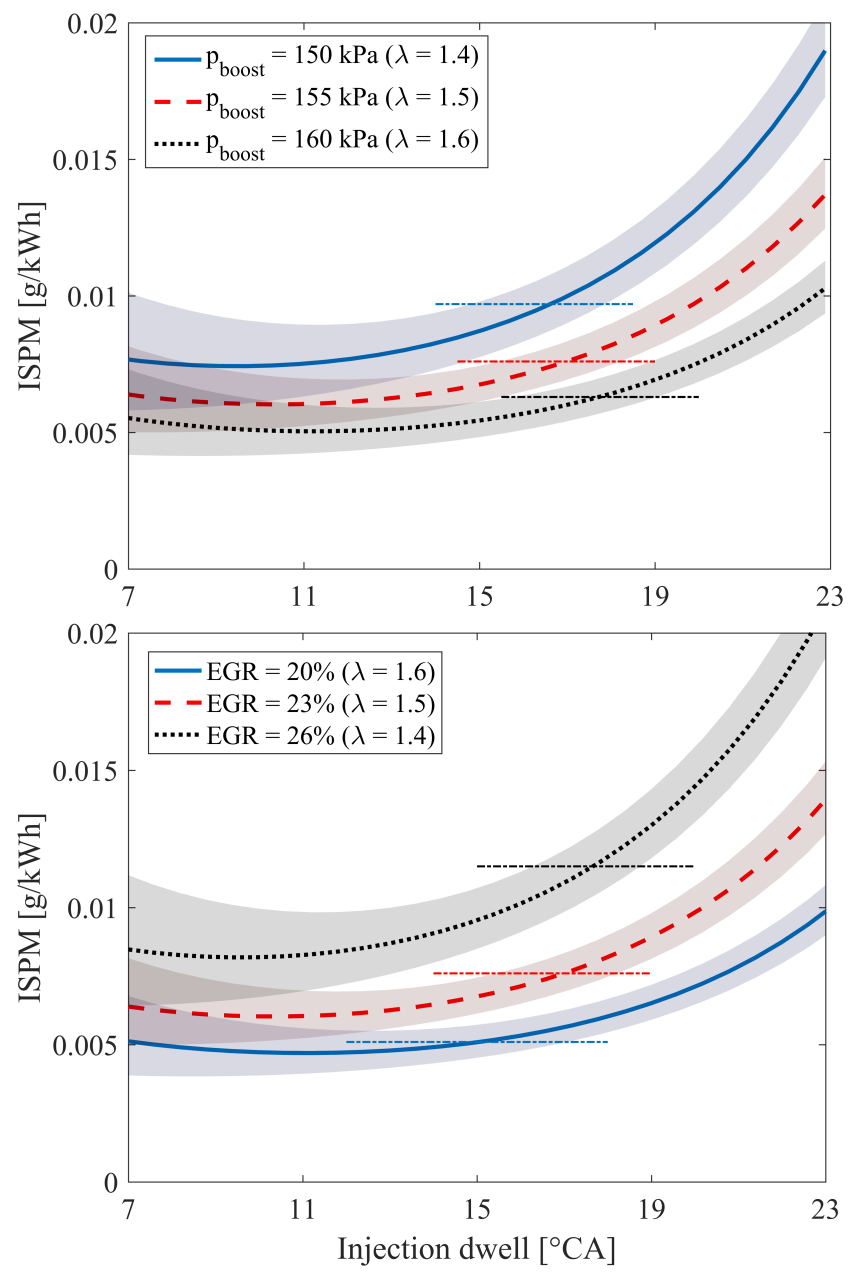

Figure 7. ISPM emissions as function of dwell for three boost pressures (top) and EGR rates (bottom). Remaining operating conditions are set to their center point value. Single injection emission levels are indicated with the dashed horizontal lines in matching colors.

Despite strong similarities between the two graphs in Figure 7, there are also differences to note. First, absolute levels of ISPM are slightly higher for varying EGR rates compared to boost pressure. Increasing EGR has a strong reducing effect on both global and local temperatures, thereby posing a penalty on soot oxidation. Although changing boost pressure also has its impact on temperature, the effect is vastly different compared to varying EGR, and local temperature changes do not necessarily follow global trends. Furthermore, altering boost pressure consequently affects in-cylinder density, thereby changing mixing processes as well. Second, when looking at the soot reduction window (i.e., the injection dwell range resulting in lower ISPM), it can be seen that for increasing EGR the window widens. On the contrary, for decreasing boost pressure (thus a similar change in air-excess ratio) the window narrows. Distinctive impact of

Page 7 of 13 both parameters on in-cylinder bulk temperature are of importance here. Although governing mechanisms are difficult to distill from these results alone - nor is it in the scope of this work to identify them - the presented graphs hint at more effects playing a role; temperature effects are to be considered as well.

\section{A25 - Response to post-injection scheduling}

In the previous sections, impact of air-excess ratio and combustion phasing on post-injection efficacy was discussed. The response to variations in dwell has been charted for different air-excess ratios, showing the importance of careful selection of both post-injection timing and settings of other operating parameters. However, postinjection timing is not the only crucial parameter to be taken into account. The interplay of injection dwell and fuel split will determine the eventual efficacy of the post-injection. In this section, so-called response surfaces are presented for ISFC, ISNOx and ISPM. Other operating conditions are kept constant in their corresponding center point value. Results are presented as percentual differences with respect to the predictions of single injection regression polynomials. Negative values hence represent a reduction, whereas positive values reveal an increase.

The response surface plot of ISFC is shown in Figure 8. Notable improvements to fuel consumption are seen for a considerable area. There is also a sizeable range at an injection dwell value of about 15 ${ }^{\circ} \mathrm{CA}$ where fuel consumption is almost not responsive at all to fuel split. This observations implies that more than one mechanism or metric (i.e., heat loss, burn duration, combustion phasing) impact on the thermodynamic efficiency that seemingly cancel each other out. By carefully choosing a proper combination of dwell and split, the balance of these processes can be adjusted to obtain a reduction in fuel consumption. Especially short dwells in combination with large splits add up to more than three percent improvement at best, but smaller splits also result in more moderate efficiency gains. For dwells longer than circa $15^{\circ} \mathrm{CA}$ the benefits of a post-injection disappear regardless of fuel split values. This increase in ISFC is expected, for fuel is introduced late in the cycle, which effectively reduces the expansion ratio. As fuel split is enlarged for these long dwells the predicted fuel consumption is obviously further increasing.

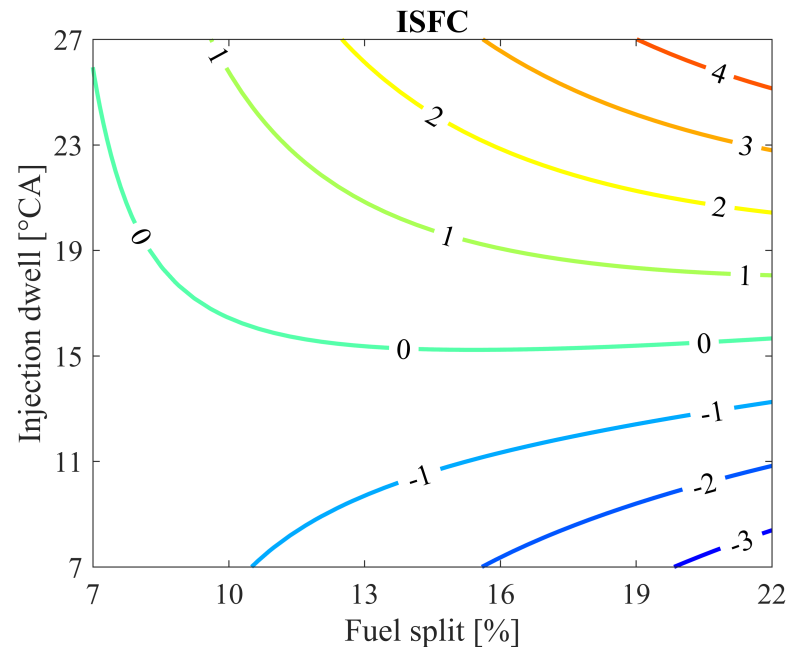

Figure 8. Response surface plot of the predicted percentual difference in ISFC as function of dwell and split for mode A25. All remaining operating conditions are kept in their center point value. 
Figure 9 depicts the response surface plot of ISPM corresponding to the results presented in Figure 8. Here, a substantial region is found where soot emissions are reduced compared to single injection operation. Interestingly, the soot reduction area spans approximately the same range of dwell and split values as the fuel consumption improvements shown in Figure 9. This 'overlap' can be an indication that improved burn-out, and a subsequent advance of the end of combustion, plays a role in the projected efficiency gains. No soot reduction is observed when the post-injection dwell is increased beyond $23^{\circ} \mathrm{CA}$; a trend that becomes stronger when larger splits are applied. Interaction between main injection soot pockets and the postinjected reacting spray is expected to be minimal, if not absent, in those cases. In the long-dwell regime, soot emissions are relatively insensitive to fuel split variations, whereas in the close-coupled regime these variations make the difference between almost negligible post-injection efficacy and soot reductions up to 40 percent. This is another implication that physical interaction between main combustion fuel residues and the post-injected reacting spray is essential for the effectiveness of post-injections.

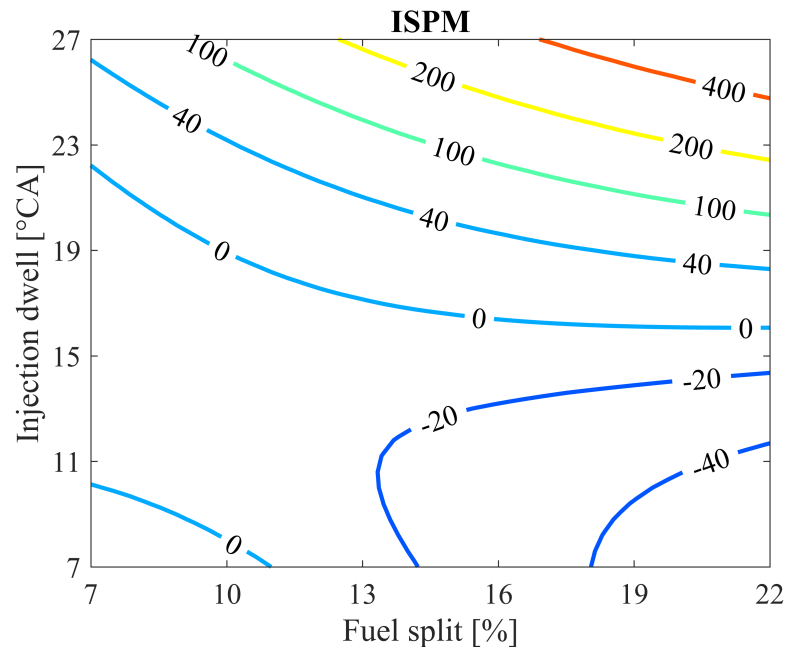

Figure 9. Response surface plot of the predicted percentual difference in ISPM as function of dwell and split for mode A25. Selected operating conditions are equal to those in Figure 9.

A response surface plot of ISNOx is presented in Figure 10. For the selected operating conditions, nearly all combinations of injection dwell and fuel split add up to a reduction of engine-out NOx levels. Although it was shown in Figure 5 that burning a portion of the fuel later in the cycle does not always result in lower NOx, the proposed mechanism does hold for the conditions treated here. The largest reduction in NOx is consequently reached for the longest dwell and largest split under consideration.

Observing Figures 8, 9 and 10 learns that there is a region of simultaneous reduction in ISPM, ISNOx and ISFC for short dwells and relatively large splits. Despite that soot reduction mechanisms are usually extensively discussed in available literature, the same cannot be said for NOx reduction and efficiency benefits. The governing processes affecting the latter two are unclear at best, and are in need of more dedicated research on, for example, optical engine rigs. Still, in-cylinder information from full-metal test engines can be of interest too, and would ideally contain predictive capabilities as regards emissions and efficiency.

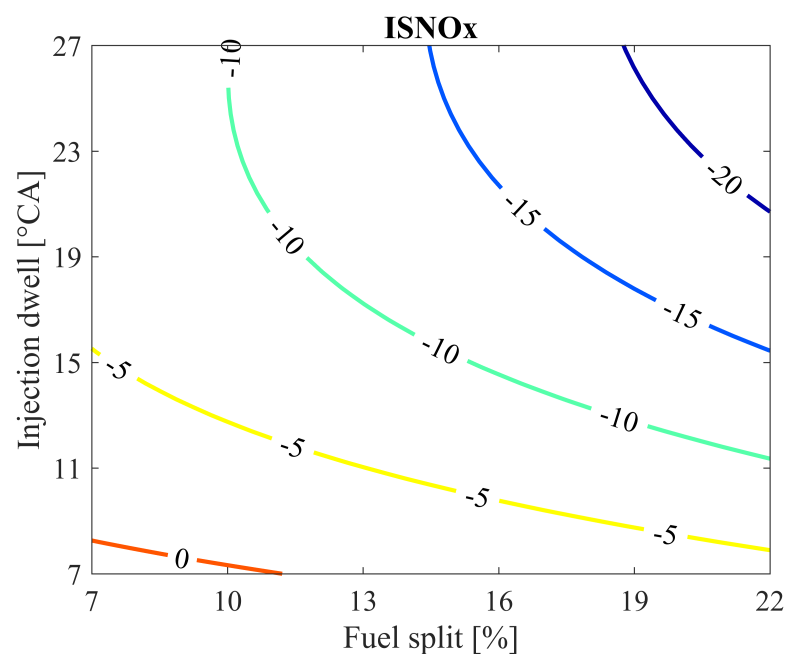

Figure 10. Response surface plot of the predicted percentual difference in ISNOx as function of dwell and split for mode A25. Operating conditions match those in Figures 9 and 10.

Figure 11 shows two cumulative heat release traces from a single injection and a post-injection experiment. Injection dwell and fuel split of the post-injection scheme are set to $7{ }^{\circ} \mathrm{CA}$ and $13.5 \%$, respectively. As all other operational parameters are equal for the two injection strategies, the combustion processes are identical up to just after TDC. Thereafter, the heat release trace of the post-injection strategy starts to level off, as burn rates decline. This is expected, for the main injection ends earlier compared to single injection operation. As a consequence, CA50 is retarded by about $0.5^{\circ} \mathrm{CA}$ for the postinjection scheme. This has a direct impact on the global in-cylinder temperature history, since a lower peak heat release rate results in a reduced maximum global temperature.

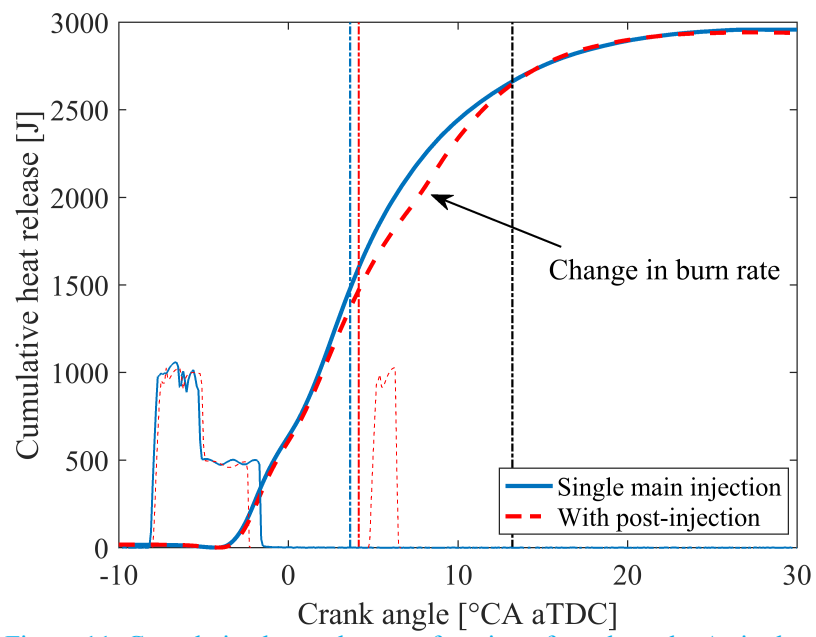

Figure 11. Cumulative heat release as function of crank angle. A single main injection is compared to a post-injection scheme using a split of $13.5 \%$ and dwell of $7{ }^{\circ} \mathrm{C}$. Actuation currents of the injector in arbitrary units are shown for reference. CA50 for each strategy is depicted with the vertical dash-dot lines in corresponding colors, whereas CA90 for both cases is indicated with the black dash-dot line.

These observations can partly explain lower NOx levels and reduced heat losses to the cylinder walls. However, a shift of CA50 further into the expansion stroke is typically associated with a deterioration of the thermodynamic efficiency. But as the post-injection is introduced around $5{ }^{\circ} \mathrm{CA}$ aTDC, the slope of cumulative heat release 
steepens again and the post-injection strategy catches up with the single main injection case. CA90 of the two strategies ultimately coincide again, making the overall burn duration equal.

\section{A50 - Interplay of main and post-injection timing}

Significant impact of main injection timing on post-injection efficacy has been observed at low load (A25). Here, the interaction of main and post-injection timing is investigated for increased load (A50). Engine speed will be kept constant with respect to previous sections to make a valid comparison. Figure 12 depicts ISPM and ISNOx trade-offs for A50 with varying main injection timing. Along each curve, main injection SOA is equally adjusted from -5 to $-12{ }^{\circ} \mathrm{CA}$ aTDC in the direction indicated by the arrow. Two post-injection strategies are subsequently compared to single injection operation; a close-coupled scheme employing a dwell of $5{ }^{\circ} \mathrm{CA}$ and a long-dwell scheme with a $15^{\circ} \mathrm{CA}$ separation from the main EOA. Other operating conditions are set to their center point value.

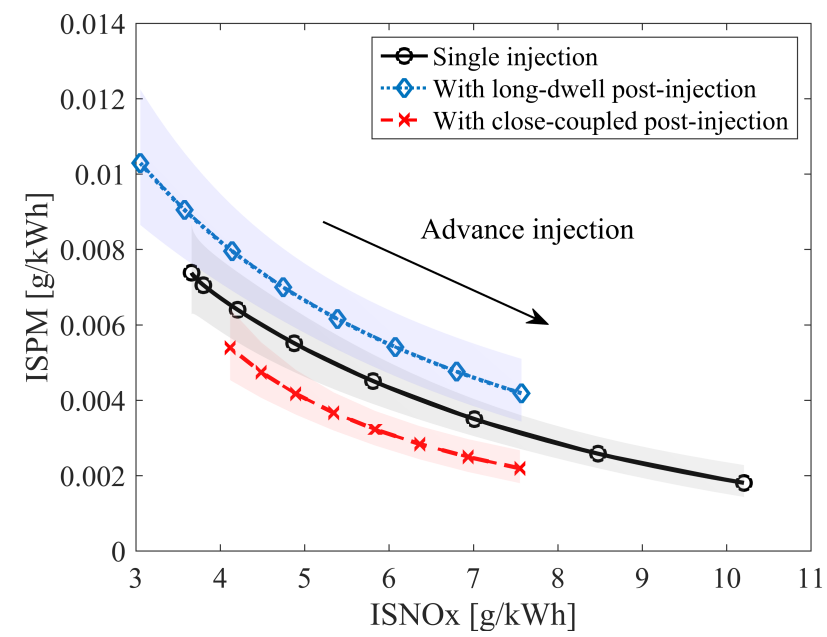

Figure 12. Predicted trade-off of ISNOx and ISPM. A single main injection is compared to a close-coupled $\left(5^{\circ} \mathrm{CA}\right)$ and a long-dwell $\left(15^{\circ} \mathrm{CA}\right)$ postinjection strategy. Markers are added to indicate fixed main injection timings with intervals of $1{ }^{\circ} \mathrm{CA}$.

It becomes clear from Figure 12 that phasing of the combustion event does not have the impact seen at low load. Shown trade-offs do not intersect, but rather exhibit an overall offset. Instead, scheduling of the post-injection is the crucial factor here. While a close-coupled post-injection scheme outperforms the single main injection strategy over the entire range, a long-dwell scheme does the opposite. This apparent small margin on post-injection dwell can partly be explained by the selection of center point values in the DoE matrix. Resulting single pulse ISPM values are all well within EURO VI legislative limits $(0.01 \mathrm{~g} / \mathrm{kWh})$. An improved burn-out of in-cylinder soot at higher load stemming from elevated overall temperatures together with an increased fuel pressure are valid explanations, although the actual engine-out soot quantity naturally depends on the full engine calibration. Still, the soot reduction capabilities are preserved at higher loads, albeit less margin on the selection of dwell is found.

In Figure 13, the predicted trade-offs of ISNOx and ISFC are shown for conditions corresponding to Figure 12. Both post-injection strategies are incapable of improving fuel consumption, although differences diminish towards the earliest of main injection timings. Confidence intervals of the predictions partially overlap leaving the

Page 9 of 13 possibility that actual values are (near) identical. Substantial ISNOx reductions are observed for post-injection strategies in the region of early main injection timings, which can be an interesting feature for selective catalytic reduction (SCR) systems typically found in EURO VI engines. These aftertreatment systems are used to reduce tailpipe emissions of NOx and require additional urea-based liquids to be stored and utilized on board, which thus increase the total cost of operation. Despite that these particular post-injection strategies do not result in engine efficiency gains at elevated load, the actual benefit can be found in reduced costs of aftertreatment operation.

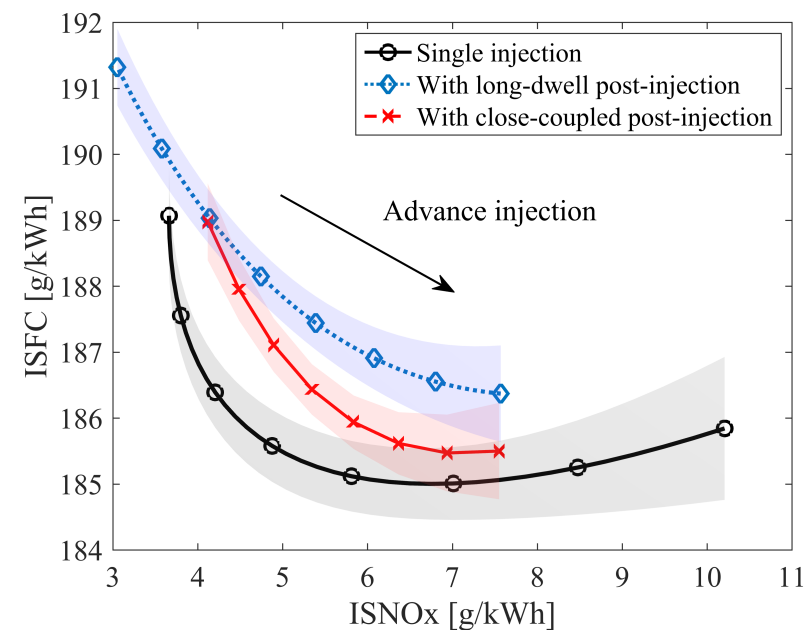

Figure 13. Predicted trade-off of ISNOx and ISFC. Operating conditions are equal to those in Figure 13.

\section{A50 - Response to post-injection scheduling}

The interaction of injection dwell and fuel split will be assessed similarly to the low load case. As Figure 13 already presumed, a reduction in fuel consumption by adding a post-injection event might be more of a challenge compared to the A25 mode. Figure 14 depicts the percentual difference in ISFC of a post-injection scheme with respect to single injection operation. No reduction in ISFC is achieved regardless of dwell-split combination.

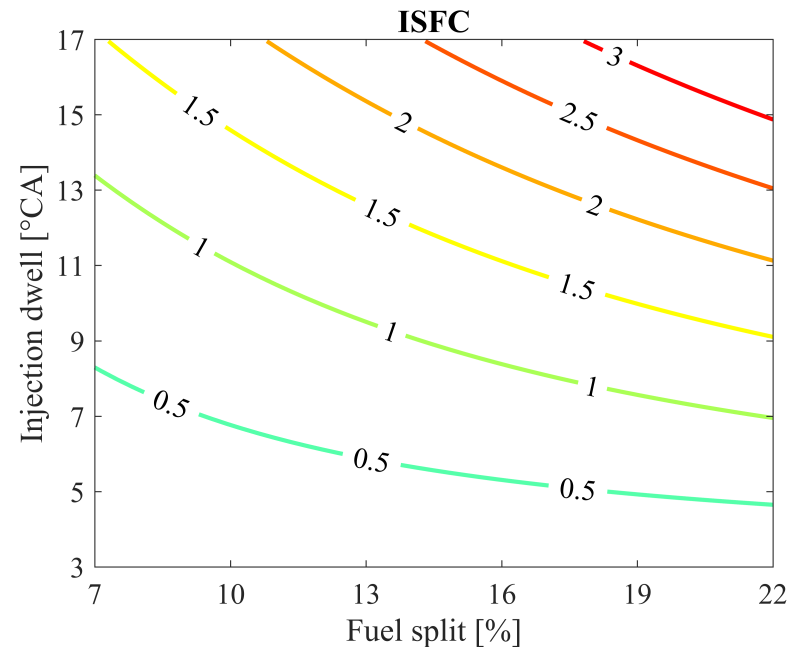

Figure 14. Response surface plot of the predicted percentual difference in ISFC as function of dwell and split for mode A50. Other operating conditions are set to their center point value. 
A deteriorating trend is seen at this elevated load when both fuel split and injection dwell are simultaneously increased, similar to the low load scenario shown in Figure 8. It is worth noting that the detrimental impact on fuel consumption seems to be primarily caused by extending the injection dwell, as the projected slopes are steep at any given split value. Conversely, an increasing fuel split is evidently making less of a difference. How the impact of a post-injection on engine efficiency changes with load remains yet unclear, but these results once again show signs of multiple mechanisms being at play. Note that the fuel pressure is significantly elevated with respect to A25, rendering it apparently difficult to improve the thermodynamic efficiency by adding a post-injection.

Figure 15 shows the response surface plot of ISPM reduction. The soot reduction capabilities seen at lower loads are preserved at A50, albeit the maximum obtained reduction is somewhat smaller. Increased fuel pressures can partly account for the apparent lower efficacy of the post-injection as regards engine-out soot levels. Furthermore, it was previously argued that burn-out is more effective at higher load due to elevated global temperatures. The area in which soot reductions are observed is considerably smaller compared to lower load (A25). However, contemporary fuel injection equipment is more than capable to provide sufficiently accurate timing and quantity for even very short fuel pulses to target these areas. Especially fuel split values need to be lowered with respect to low load (see Figure 9) in order to reduce ISPM, whereas the closecoupled dwell regime again shows the highest efficacy. As the postinjection is mainly employed to improve late-cycle oxidation of main-injected fuel residues, a substantially longer post-injection will not be beneficial.

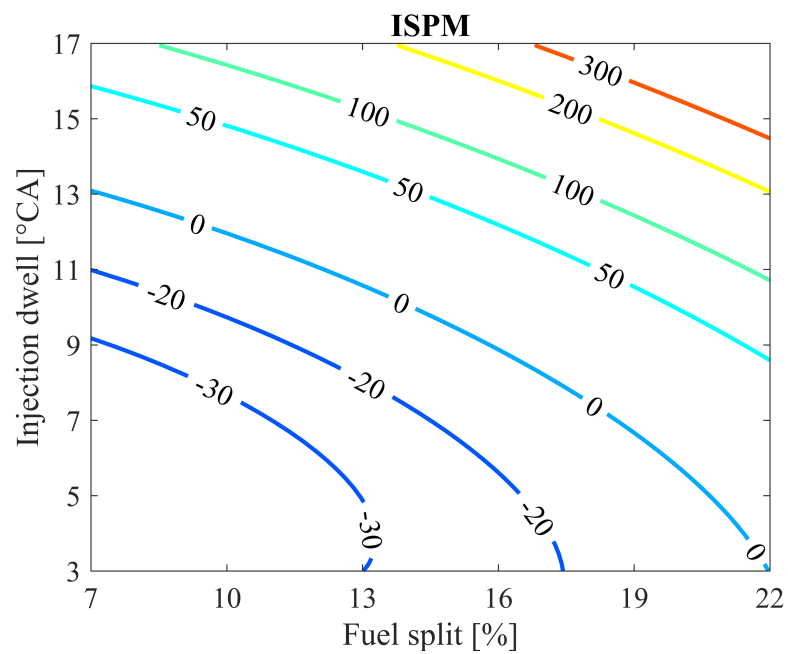

Figure 15. Response surface plot of the percentual difference in ISPM as function of dwell and split for mode A50.

The response surface plot of percentual difference in ISNOx is depicted in Figure 16. A reduction in NOx emissions is clearly not as easily obtained at higher load. Increments in excess of $20 \%$ are seen for very short dwells in combination with large splits. The trade-off with ISPM as seen in Figure 15 is evident, since regions with soot reduction are in line with areas of NOx increase, and vice versa. But when the post-injection dwell is amply extended, a reduced global temperature in which the post-injected fuel is burned proves to be effective in diminishing NOx formation. Again, the longest dwell and largest split combination results in the most prominent reduction. Still, this reduction in ISNOx in the long-dwell regime is accompanied with considerable increments in both ISPM and ISFC making these areas highly undesired.

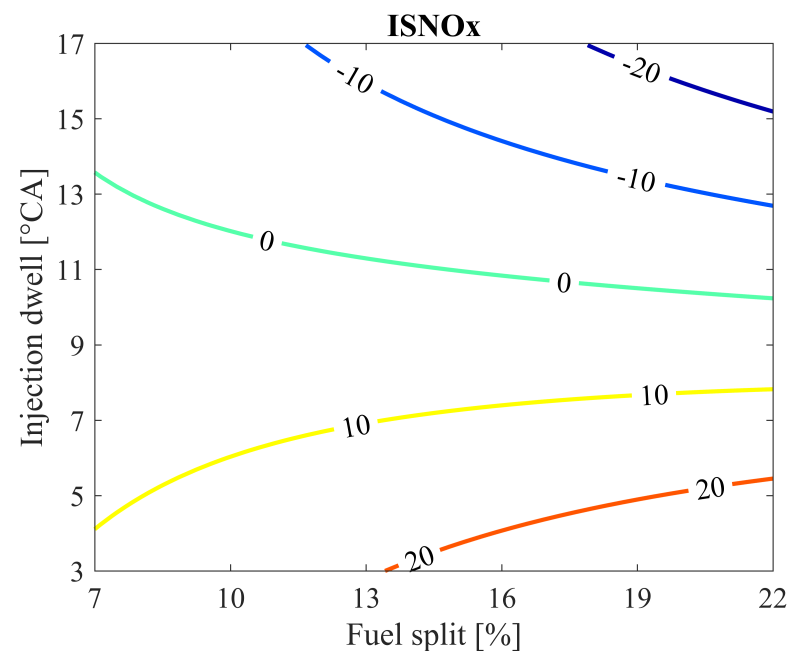

Figure 16. Response surface plot of the percentual difference in ISNOx as function of dwell and split for mode A50.

\section{B50 - Influence of fuel pressure}

Increasing fuel pressure is a common measure to achieve a high thermodynamic efficiency. As burn rates are dependent on the rate of fuel injection in diffusion-limited combustion, the total burn duration can be reduced by increasing fuel pressure. This is especially useful when engine speed is increased, since the residence time at high pressure and temperature is shorter and thus less time is available to complete chemical reactions. Here, an assessment is done on the possibility to further improve engine efficiency using fuel pressure in a post-injection strategy.

Figure 17 shows a predicted trade-off between ISFC and ISNOx at mode B50. A single main injection is again compared to a postinjection scheme with a fixed dwell $\left(12.5^{\circ} \mathrm{CA}\right)$ and split $(10 \%)$. Fuel pressure is equally varied from 1325 to 1825 bar for both strategies. Increasing fuel pressure certainly has benefits in terms of fuel consumption for both shown injection schemes. This comes at a cost of increased engine-out NOx levels, for the corresponding increase in burn rate results in elevated peak temperatures. Eventually, the positive impact on fuel consumption might even reverse as the increasing peak temperatures lead to a rise in total heat loss. Further, when brake specific fuel consumption is considered, this extremum is possibly revealed at an even lower fuel pressure. The latter is a consequence of fuel pump power necessary to pressurize the common rail, which is absent for the engine used in this work since an external high-pressure pump is used. Nevertheless, the projected trade-offs shown in Figure 17 display a decreasing trend in fuel consumption over the entire range, while ISNOx steadily increases. The postinjection strategy, however, outperforms the single main injection. As fuel pressure is increased, the predicted downward slope is steeper when utilizing a post-injection. The aforementioned compromise between increased burn rate and higher heat loss rate at elevated fuel pressure seems to be favorable when using a post-injection scheme. Splitting the heat release results in a reduction of peak temperature, while the elevated fuel pressure is able to attain a sufficiently short combustion duration needed for efficient conversion of chemical heat to mechanical work. 


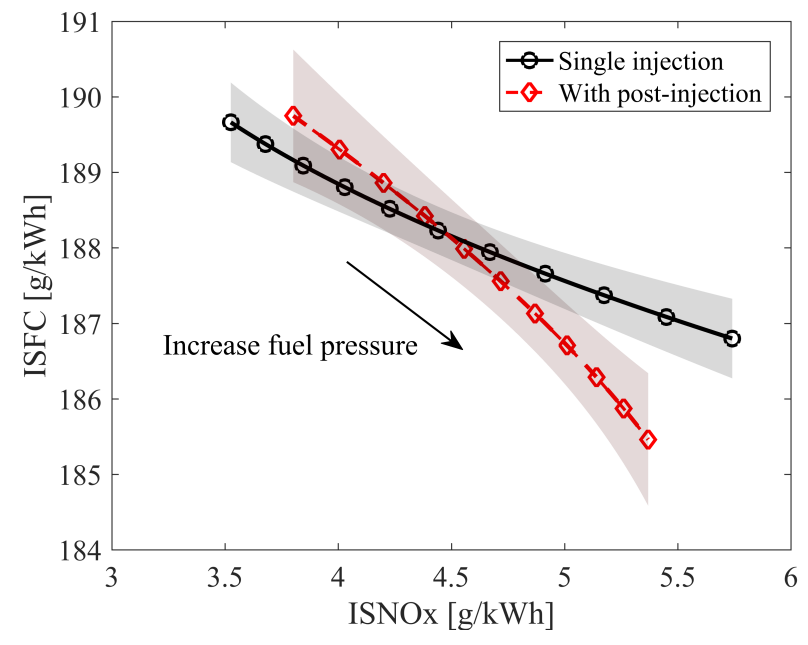

Figure 17. Predicted ISFC and ISNOx trade-off. Markers indicate fixed fuel pressures with intervals of 50 bar. Post-injection parameters are fixed at a dwell of $7.5^{\circ} \mathrm{CA}$ and a split of $10 \%$. Boost pressure equals $2.1 \mathrm{bar}$, while other operating parameters are set to their center point value.

\section{B50 - Response to post-injection scheduling}

A reduction in fuel consumption at $\mathrm{B} 50$ was already shown to be feasible in the previous section. The interaction of fuel split and injection dwell will again be assessed here using response surfaces. The response surface of ISFC at B50 is shown in Figure 19. A large region with only moderate efficiency improvements is seen for dwell values below $10{ }^{\circ} \mathrm{CA}$. Fuel split is certainly less influential, as earlier observed at A50 in Figure 14. Operating at the A-speed has revealed that an earlier completion of combustion by applying a post-injection is difficult to achieve. Measurements shown in Figure 14 do reveal that an increased burn rate of the post-injected fuel is possible, although this ultimately did not advance CA90. The efficiency gains were rather hypothesized to stem from a reduction in total heat loss. A general change is seen when running at the B-speed in the sense that an advancement of CA90 with respect to single injection operation is more common.

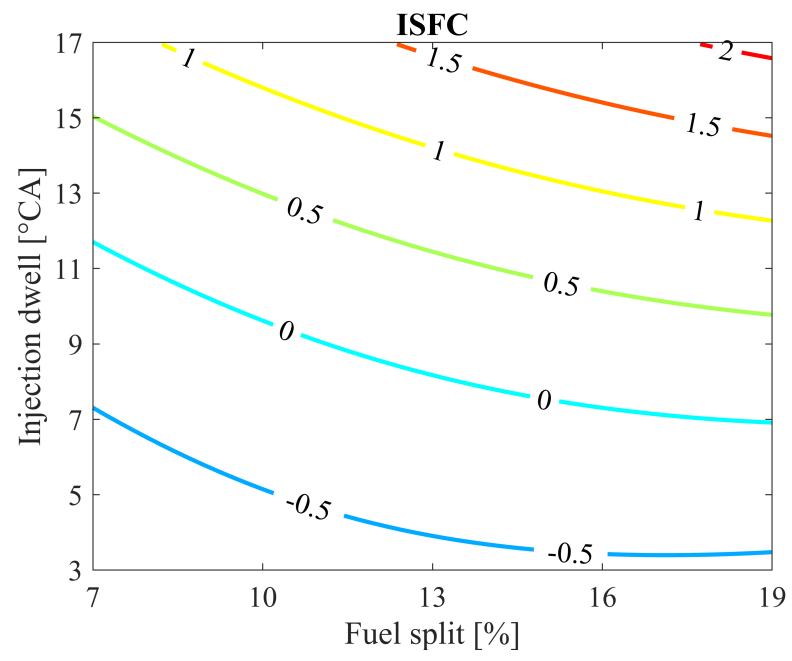

Figure 19. Response surface plot of the percentual difference in ISFC as function of dwell and split for mode B50. Other operational parameters are set to their center point value.

Page 11 of 13
This suggests that at higher engine speed the mechanisms leading to reduced fuel consumption are not necessarily the same as at the Aspeed, but are instead more frequently accomplished by shortening the burn duration. Since combustion generally spans a larger crank angle interval at elevated engine speed, due to the fact that combustion reactions need a certain time to complete, there is more opportunity to accelerate the late phase of combustion by adding a post-injection.

The percentual difference in ISPM between a single main injection and a post-injection strategy at B50 is shown in Figure 20. Again, it can be seen that the soot reduction capabilities are preserved. The area in which soot reductions are obtained is enlarged compared to A50. Similar as for the ISFC response in Figure 19, the generally longer burn duration at higher engine speed appears to benefit more from the enhanced oxidation effect that a post-injection has on the burn-out phase. Further, maximal soot reduction is seen for slightly larger fuel splits. Although this engine has a low-swirl design, swirl velocities -and bulk flow velocities in general- somewhat increase with engine speed. Thus, a post-injection profits from an increased duration of the imposed post-spray momentum to penetrate the bulk flow and interact with the soot clouds originating from the main combustion event. This is readily achieved by extending the injector actuation duration for the post-injection event.

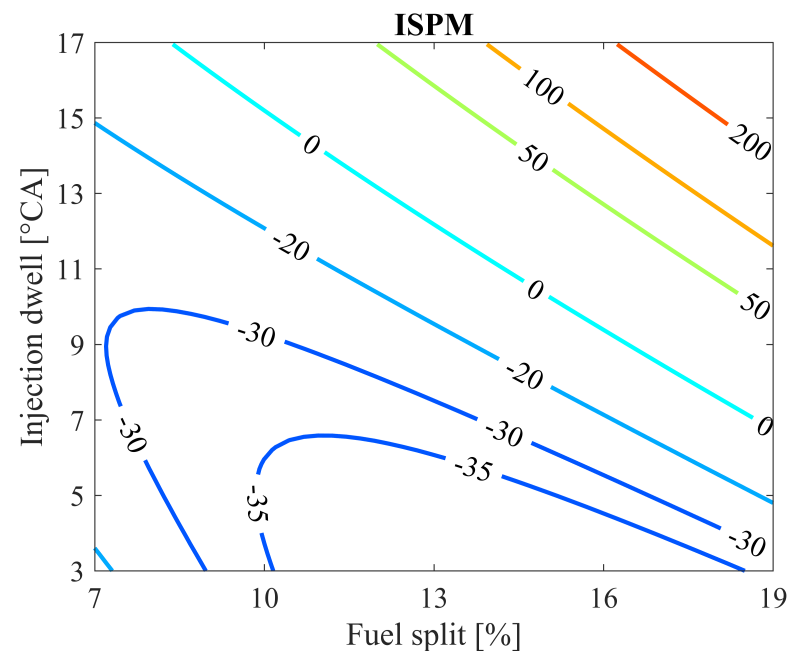

Figure 20. Response surface plot of the percentual difference in ISPM as function of dwell and split for mode B50.

Figure 21 depicts the ISNOx response surface for B50. Reduction of engine-out NOx levels are obtained in the long-dwell regime, whereas a large split further amplifies the reduction. Although this trend is seen for all three load-speed combination under investigation, only A50 and B50 show considerable increases of ISNOx in the close-coupled regime. Introducing fresh air into hot combustion products, thereby changing the stoichiometry towards conditions of enhanced NOx formation rates seems to mainly occur at higher load, which is possibly linked to the longer residence time at higher global temperature. The post-injection therefore needs to be delayed significantly longer compared to low load in order to mitigate NOx formation rates. The trade-off with ISPM is evident, which reduces the usefulness of post-injections at higher load, although a broader optimization is needed to investigate the potential of post-injection strategies in the entire load-speed map. 


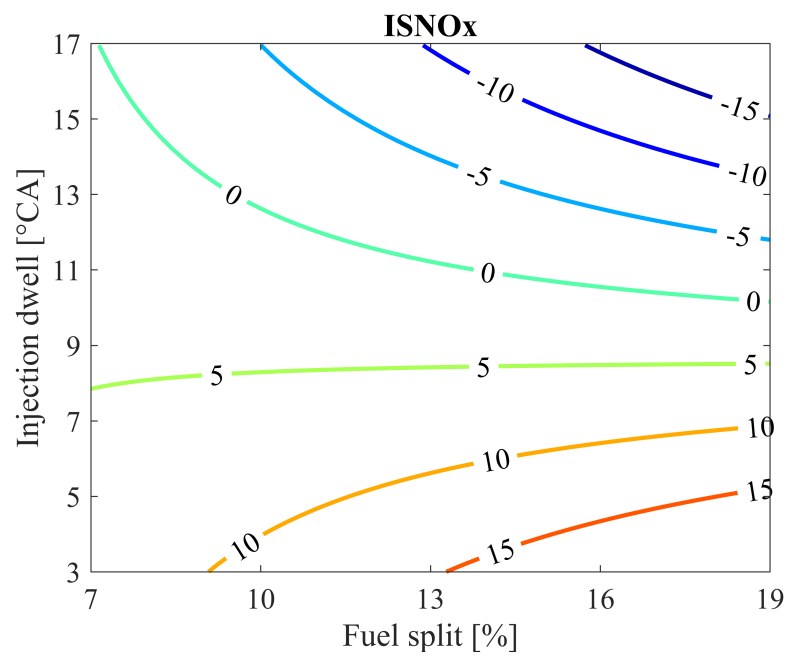

Figure 21. Response surface plot of the percentual difference in ISNOx as function of dwell and split for mode B50. Operational parameters correspond with Figure 19 and Figure 20.

\section{Conclusions}

The present study uses a Design-of-Experiments approach to investigate the impact of air path and fueling parameters on postinjection efficacy. The main conclusions of this work are:

1. At mode A25, the interplay of EGR rate and main injection timing shows potential for simultaneous reduction of fuel consumption and engine-out NOx levels with only a marginal increase in soot emissions. Applying a post-injection at elevated EGR rates allows for advancing the combustion event to obtain higher engine efficiency, while mitigating NOx formation rates.

2. The air-excess ratio has a strong impact on the soot reduction capabilities of a post-injection seen at A25. Lower air-excess ratios increase the total reduction in engine-out soot. Moreover, optimal post-injection dwell is shortened when air-excess ratios are decreased. These observations suggest that indeed improved late-cycle mixing of fuel (remnants) and oxidizer play an important role in the overall efficacy of post-injection strategies.

3. Appropriate selection of post-injection dwell and split at A25 was found to simultaneously reduce engine-out soot and NOx, as well as fuel consumption. A relatively large, close-coupled post-injection results in significant reductions of soot and fuel consumption, while also moderately diminishing NOx levels.

4. At mode A50, advancing the main injection timing in a closecoupled post-injection scheme demonstrated the capability to concurrently reduce NOx and soot emissions. This ability did not hold for a long-dwell strategy.

5. Although modest engine-out soot reductions have been accomplished for mode A50 by selecting a close-coupled dwell and relatively small split, it comes at the cost of an increase in fuel consumption. A reduction in fuel consumption has not been established at A50 altogether, which considerably reduces the usefulness of a post-injection strategy for this particular loadspeed combination.
6. Moderate reductions in fuel consumption and soot are seen for mode B50 when utilizing a close-coupled post-injection. These reductions come at the expense of increased NOx emissions.

7. At mode B50, employing a post-injection strategy at elevated fuel pressure demonstrated higher engine efficiency than single injection operation, while NOx levels are reduced as well.

Future work will focus on application of an optimization method (e.g. desirability approach) to fully utilize the regression polynomials presented in the current work. The fueling schemes will be extended with (multiple) pilots and/or post-injections to further investigate the potential of multiple-injection strategies. Attention will moreover be directed towards higher engine speeds, since the work presented here hints that increasing load at particularly the A-speed is not the most promising operational mode for splitting injection events.

\section{References}

1. Chen, S.K., "Simultaneous Reduction of NOx and Particulate Emissions by Using Multiple Injections in a Small Diesel Engine," SAE Technical Paper, 2000-01-3084, 2000, doi: $10.4271 / 2000-01-3084$

2. Badami, M., Mallamo, F., Millo, F., and Rossi, E.E, "Influence of Multiple Injection Strategies on Emissions, Combustion Noise and BSFC of a DI Common Rail Diesel Engine," SAE Technical Paper, 2002-01-0503, 2002, doi: 10.4271/2002-01-0503

3. Desantes, J.M., Arrègle, J., Javier López, J., and García, A, "A Comprehensive Study of Diesel Combustion and Emissions with Post-injection," SAE Technical Paper, 2007-

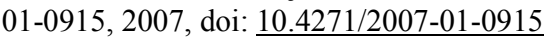

4. Vanegas, A., Won, C., Felsch, M., Gauding, M., and Peters, N., "Experimental Investigation of the Effect of Multiple Injections on Pollutant Formation in a Common-Rail DI Diesel Engine," SAE Technical Paper, 2008-01-1191, 2008, doi: 10.4271/2008-01-1191

5. Benajes, J., Molina, S., and García, J.M., "Influence of Preand Post-Injection on the Performance and Pollutant Emissions in a HD Diesel Engine," SAE Technical Paper, 2001-01-0526, 2001, doi: 10.4271/2001-01-0526

6. Payri, F., Benajes, J., Pastor, J.V., and Molina, S., "Influence of the Post-Injection Pattern on Performance, Soot and NOx Emissions in a HD Diesel Engine," SAE Technical Paper, 2002-01-0502, 2002, doi: 10.4271/2002$\underline{01-0502}$

7. Sperl, A., "The Influence of Post-Injection Strategies on the Emissions of Soot and Particulate Matter in Heavy Duty Euro V Diesel Engine," SAE Technical Paper, 2011-360350, 2011, doi: 10.4271/2011-36-0350

8. O'Connor, J. and Musculus, M., "Post Injections for Soot Reduction in Diesel Engines: A Review of Current Understanding," SAE Int. J. Engines 6(1):400-421, 2013, doi: $\underline{10.4271 / 2013-01-0917}$

9. Hotta, A., Inayoshi, M., and Nakakita, K., "Achieving Lower Exhaust Emissions and Better Performance in an HDSI Diesel Engine with Multiple Injection," SAE Technical Paper, 2005-01-0928, 2005, doi: $10.4271 / 2005-$ $\underline{01-0928}$

10. Mingfa, Y., Hu, W., Zunqing, Z., and Yan, Y., "Experimental Study of Multiple Injections and Coupling Effects of Multi-Injection and EGR in a HD Diesel Engine," SAE Technical Paper, 2009-01-2807, 2009, doi: 10.4271/2009-01-2807 
11. Rakesh, B., Bakara, A.S., and Sarware, A., "Effect of Fuel Injection Parameters and EGR on Exhaust Emission of a $3 \mathrm{~L}$ Diesel Engine," SAE Technical Paper, 2015-01-2814, 2015, doi: 10.4271/2015-01-2814

12. Horibe, N., Komizo, T., Sumimoto, T., Wang, H., and Ishiyama, T., "Smoke Reduction Effects by Post Injection for Various Injection Parameters and Combustion Chamber Shapes in a Diesel Engine," SAE Technical Paper, 2014-012634, 2014, doi: 10.4271/2014-01-2634

13. Horibe, N., Komizo, T., Mamizuka, Y., Sumimoto, T., Kawanabe, H., and Ishiyama, T., "Analysis of Mixture Formation Process in a Diesel Engine with Post Injection," SAE Technical Paper, 2015-01-1836, 2015, doi: 10.4271/2015-01-1836

14. Montgomery, D.T. and Reitz, R.D., "Optimization of Heavy-Duty Diesel Engine Operating Parameters Using a Response Surface Method," SAE Technical Paper, 2000-011962, 2000, doi: 10.4271/2000-01-1962

15. Montgomery, D.T. and Reitz, R.D., "Effects of Multiple Injections and Flexible Control of Boost and EGR on Emissions and Fuel Consumption of a Heavy-Duty Diesel Engine," SAE Technical Paper, 2001-01-0195, 2001, doi: 10.4271/2001-01-0195

16. d'Ambrosio, S. and Ferrari, A. "Potential of multiple injection strategies implementing the after shot and optimized with the design of experiments procedure to improve diesel engine emissions and performance," Applied Energy 155: 933-946, 2015, doi: 10.1016/j.apenergy.2015.05.124

17. Martin, J., Sun, C., Boehman, A., and O'Connor, J., "Experimental Study of Post Injection Scheduling for Soot Reduction in a Light-Duty Turbodiesel Engine," SAE Technical Paper, 2016-01-0726, 2016, doi: 10.4271/2016$\underline{01-0726}$

18. Christian, R., Knopf, F., Jaschek, A., Schindler, W., "Eine Neue Messmethodik der Bosch-zahl mit Erhörter Empfindlichkeit," MTZ 54:16-22, 1993.

19. Northrop, W. F., Bohac, S.V., Chin, J., Assanis, D.N., "Comparison of Filter Smoke Number and Elemental Carbon Mass From Partially Premixed Low Temperature Combustion in a Direct-Injection Diesel Engine," J. Eng. Gas Turbine Power 133(10), 2011, doi: 10.1115/1.4002918

20. Pandurangi, S., Frapolli, N., Bolla, M., Boulouchos, K., "Influence of EGR on Post-Injection Effectiveness in a Heavy-Duty Diesel Engine Fuelled with n-Heptane," SAE Int. J. Engines 7(4):2014, doi: 10.4271/2014-01-2633

\section{Contact Information}

R.C. Willems

Eindhoven University of Technology

Department of Mechanical Engineering

Multiphase and Reactive Flows

$\mathrm{T}+31402472877$

F +31402433445

R.C.Willems@tue.nl www.tue.nl/combustion

P.O. Box 513, Gem-N. 1.20

5600 MB Eindhoven

The Netherlands

\section{Acknowledgments}

Funding for this work was provided by the Dutch Technology Foundation TTW (Heat2Control; project 12678). Delphi Technologies and DAF Trucks are also acknowledged for their contributions. The authors particularly wish to thank Bogdan Albrecht and Tony Simpson for valuable discussions and advise.

\section{Abbreviations}

DoE Design-of-Experiments

ESC European Stationary Cycle

FSN Filter Smoke Number

TDC Top Dead Center

EGR Exhaust Gas Recirculation

SOA Start Of Actuation

EOA End Of Actuation

ISFC Indicated Specific Fuel Consumption

ISNOx Indicated Specific Nitrogen Oxides

ISPM Indicated Specific Particulate Matter

aROHR Apparent Rate of Heat Release 